\title{
8
}
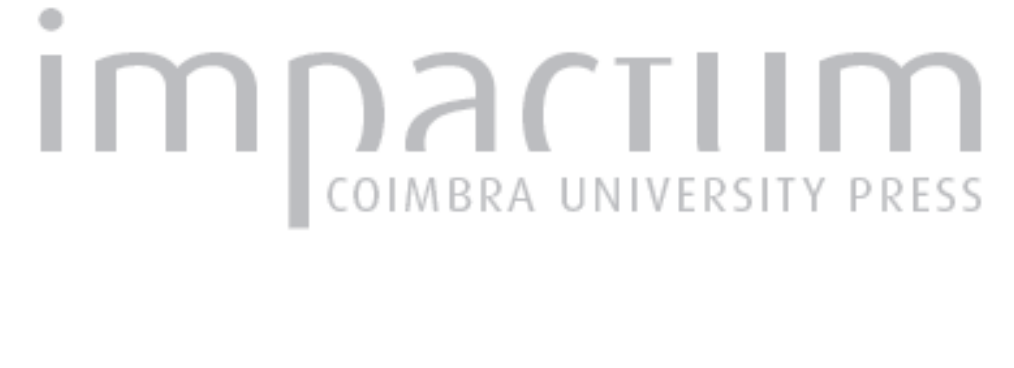

\section{Para que serve o Provedor?: a eficácia do Provedor do serviço público de rádio e televisão}

Autor(es): $\quad$ Ferro, Hugo

Publicado por: Imprensa da Universidade de Coimbra

URL persistente:

URI:http://hdl.handle.net/10316.2/39189

DOI:

DOI:http//dx.doi.org/10.14195/2183-6019_2_7

Accessed : $\quad$ 26-Apr-2023 14:59:01

A navegação consulta e descarregamento dos títulos inseridos nas Bibliotecas Digitais UC Digitalis, UC Pombalina e UC Impactum, pressupõem a aceitação plena e sem reservas dos Termos e Condições de Uso destas Bibliotecas Digitais, disponíveis em https://digitalis.uc.pt/pt-pt/termos.

Conforme exposto nos referidos Termos e Condições de Uso, o descarregamento de títulos de acesso restrito requer uma licença válida de autorização devendo o utilizador aceder ao(s) documento(s) a partir de um endereço de IP da instituição detentora da supramencionada licença.

Ao utilizador é apenas permitido o descarregamento para uso pessoal, pelo que o emprego do(s) título(s) descarregado(s) para outro fim, designadamente comercial, carece de autorização do respetivo autor ou editor da obra.

Na medida em que todas as obras da UC Digitalis se encontram protegidas pelo Código do Direito de Autor e Direitos Conexos e demais legislação aplicável, toda a cópia, parcial ou total, deste documento, nos casos em que é legalmente admitida, deverá conter ou fazer-se acompanhar por este aviso. 
revista de comunicação,

jornalismo e espaço público

2

Periodicidade

Semestral

Imprensa da Universidade de Coimbra Coimbra University Press

\section{mediapolis}

tema

os desafios dos media

de serviço público

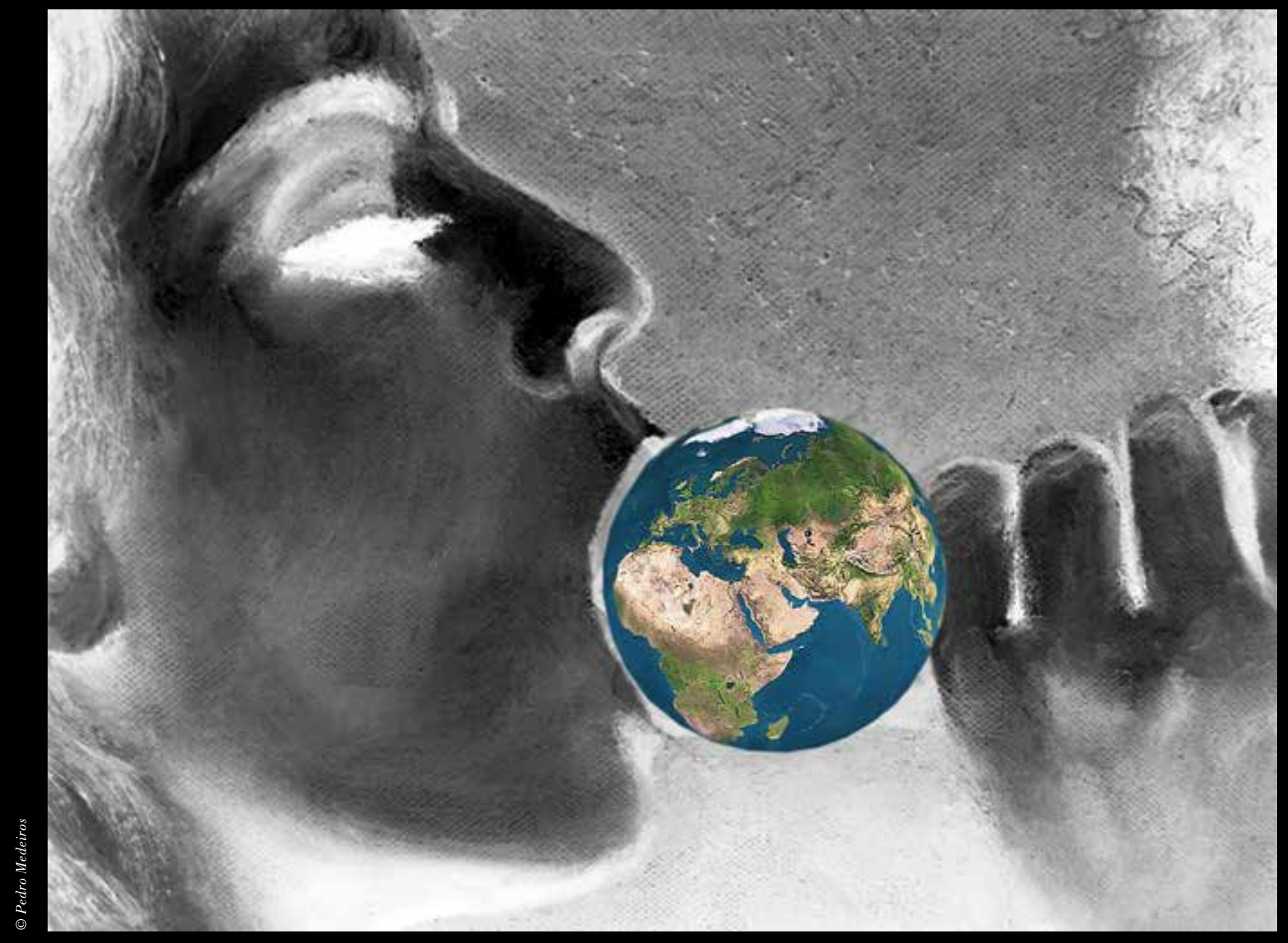




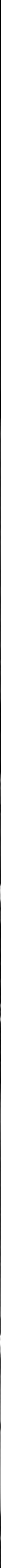




\title{
Para que serve o Provedor?
}

\section{A eficácia do Provedor do serviço público de rádio e televisão}

\author{
What is the Ombudsman for? \\ The competence of the public service broadcaster Ombudsman
}

\section{Resumo:}

Este artigo pretende avaliar e discutir o papel e a eficácia das figuras do provedor do ouvinte e do provedor do telespectador do serviço público de rádio e televisão, apoiado numa conceptualização teórica que nos permite fazer uma breve reconstrução histórica do surgimento dos primeiros provedores no panorama mediático português, tentando demonstrar as vantagens e desvantagens da existência de uma figura de mediação entre os meios audiovisuais do serviço público e as audiências, recorrendo aos relatórios de atividades dos diversos provedores do ouvinte e do telespectador. Concluímos que, apesar de se terem debatido com alguns obstáculos e contingências iniciais, há uma grande diferença quanto à aceitação e ao respeito pela figura do provedor no interior das redações dos diversos órgãos de serviço público, desde que surgiram até aos dias de hoje, o que se traduz num indício de uma maior aceitação da crítica, quer por parte dos jornalistas, quer por parte dos responsáveis, no sentido de melhorar a qualidade da informação, da programação e do compromisso com as audiências.

Palavras-chave: Serviço público, autorregulação, provedores.

\section{Abstract:}

This paper aims to review and discuss the role and effectiveness of the ombudsmen of the public service broadcasting in Portugal, supported by a theoretical conceptualization that allows us to make a brief historical reconstruction of the emergence of the first ombudsmen in the Portuguese media landscape, trying to demonstrate the advantages and disadvantages of having a figure of mediation between the public audiovisual media service and the audiences, analysing the activity reports of the ombudsmen.

We conclude that despite having debated with some initial obstacles and contingencies, there is a big difference on the acceptance and respect for the ombudsman of the public service of radio and television, since it emerged up to today, which represents an indication of a greater acceptance of criticism, both by journalists and mangement, to improve the quality of information, programming and the commitment with the audiences.

Keywords: Public Service, self-regulation, ombudsmen. 
Perante a atual discussão e incerteza do futuro do serviço público de rádio e de televisão em Portugal, os provedores assumem-se como uma importante ponte entre os ouvintes, os telespectadores e a empresa concessionária e como uma das principais formas de indagar a satisfação das audiências relativamente aos conteúdos emitidos. A sua importância é relevante para os legisladores e, por esse motivo, foi-lhes dedicado um capítulo na Lei n. ${ }^{\circ} 8 / 2007$ de 14 de fevereiro que procede à reestruturação da concessionária do serviço público de rádio e televisão.

Desde a sua origem até aos dias de hoje, foram vários os autores que se dedicaram ao estudo da figura do provedor ou ombudsmam (como foi originalmente designado), nas suas diferentes vertentes, catalogando-o sempre como uma plataforma de diálogo entre jornalistas, diretores, programadores e audiências que, embora não sendo uma garantia absoluta de qualidade, é, pelo menos, uma esfera de influência tanto para fora como para dentro de portas do meio de comunicação em que atua, contribuindo para uma melhoria do conhecimento mútuo e uma maior compreensão dos processos comunicativos por parte do público.

Claude-Jean Bertrand (1997) inventariou um conjunto de procedimentos a que chamou "Meios para Assegurar a Responsabilidade Social dos Media (M.A.R.S.)", como forma de os tornar responsáveis perante o público, a partir de um conjunto de experiências efetuadas nos Estados Unidos da América (EUA) nos anos 1960, sustentados na necessidade de associação do público ao processo crítico da atividade dos media. Os M.A.R.S., apresentados por Bertrand (1997: 100-112), traduzem-se num conjunto de documentos escritos (quadros de correção, correio dos leitores, questionários de exatidão, circulares internas, cartas ou códigos deontológicos), indivíduos ou grupos (ombudsman, conselheiros de deontologia, críticas internas, júri de utentes representativo do público do jornal, associações, conselho de imprensa, conselho de disciplina, etc) e processos (educação universitária, formação contínua, estudos de opinião, auditorias deontológicas, etc.).

É no seguimento destas ideias que se enquadra o objeto de estudo deste artigo, o ombudsman, cujo surgimento, enquadramento histórico e competências abordaremos de seguida.

\section{Génese e competências do provedor}

De um ponto de vista histórico, o primeiro ombudsman foi nomeado, em 1967, pelo Louisville Courrier Journal, sedeado no Kentucky, embora existam relatos de que, já em 1913, Ralph $\mathrm{Pu}$ litzer tinha criado um gabinete de exatidão e equidade para receber as queixas dirigidas ao New York World (Bertrand, 1997: 105). Daniel Cornu confirmou esta ideia, assegurando que:

É portanto à imprensa americana que ficaremos a dever a introdução em vários jornais, segundo o modelo sueco de um ombudsman. O papel deste provedor é servir de intermediário entre a redação e o seu público, conciliar os pontos de vista, se necessário defender os interesses do leitor. Ao mesmo tempo serve de vigia, no próprio interior da redação, vela pela observação das regras deontológicas 
durante o trabalho jornalístico, lembra incessantemente a dupla exigência da informação, que é respeitar a verdade e as pessoas (Cornu, 1994: 56).

Em Portugal, o primeiro provedor surgiu no jornal desportivo Record em 1992, seguido depois pelos jornais generalistas Diário de Notícias e Público, em 1997, e Jornal de Notícias, em 2000 (Fidalgo, 2006: 521). Quando o cargo foi criado, não existia ainda uma designação concreta. Foram descartadas as hipóteses "ombudsman" - que em português seria traduzido como "ouvidor" - e "mediador", por se temer que os leitores portugueses não se adaptassem ao termo. A opção "representante dos leitores", bastante usada nos EUA, também não foi aprovada, uma vez que seria "inexata, porque se trata de alguém nomeado pela empresa jornalística, sem possuir qualquer mandato que permita falar em representação". A corrente espanhola - "defensor do leitor" - também não foi aceite porque, "para além de demasiado bélica, afigura-se inadequada", acabando por se optar pela opção “provedor" (Mesquita, 1998: 10-11).
A forma de atuação do provedor e a eficácia do seu exercício foram definidas por Mário Mesquita, do seguinte modo:

O provedor atua sempre a posteriori e os seus poderes circunscrevem-se à possibilidade de "dar voz" às vozes dos leitores, criticar o diário nas suas próprias páginas e formular recomendações e sugestões. Mas a eficácia do seu exercício dependerá, em boa parte, dos leitores, dos jornalistas e da direção da publicação. (...) O provedor será, na melhor das hipóteses, um intermediário, que poderá contribuir para reduzir o isolamento dos leitores perante o seu jornal (Mesquita, 1998: 23).

Maria José Mata (2005: 45-46) analisou a atuação dos provedores e defendeu que o tipo de atuação varia consoante a pessoa que desempenha o cargo, ou seja, para além daquilo que são os estatutos dos provedores de cada publicação há que ter sempre em conta a subjetividade inerente à personalidade e à forma com que cada provedor decide orientar a sua conduta. A autora alertou para o facto de o provedor ser uma figura independente da direção que serve de intermediário entre a publicação e o público e que "a utilidade do ombudsman para o autocontrolo dos jornalistas deve ser aferida, não apenas pelos leitores, mas sobretudo pelos elementos da própria redação." (Mata, 2002: 111).

Ou seja, o provedor não deve ser visto como um inimigo da redação e defensor das audiências, mas antes como uma espécie de ponte conciliadora entre estas duas entidades, proporcionando uma maior aproximação entre ambas.

O papel do ombudsman, jogando-se na valência de uma crítica por dentro do estabilishment, simultaneamente legitimadora e questionadora dessas ideologias, pode, no entanto, lançar as bases para uma forma de intervenção exterior e mais estruturante, suscetível de induzir no seio da redação uma nova atitude, mais interventiva e autónoma. (...) A ação do ombudsman institui novas formas de reciprocidade entre o jornal e o leitor, 
estabelecendo, entre estes, uma maior aproximação efetiva (Mata, 2002: 112- 114).

No sentido de aproximar o público e os órgãos do serviço público de rádio e televisão, foram criados os provedores do ouvinte e do telespectador da Rádio e Televisão de Portugal, em 2006, na sequência de alterações legislativas propostas pelo Governo. É a esta questão que dedicaremos a secção seguinte.

\section{Os provedores \\ do ouvinte}

\section{e do telespectador}

Em Portugal, através da Lei n. $2 / 2006$, de 14 de fevereiro, foram designados para os cargos José Nuno Martins como provedor do ouvinte e José Manuel Paquete de Oliveira como provedor do telespectador. Esta lei define que o provedor deve:

Representar e defender as perspetivas dos Ouvintes e dos Telespectadores diante da oferta radiofónica e televisiva (...) acentuar a fiabilidade do Serviço Público prestado pelas

Estações de Rádio e Televisão da RTP, SGPS, SA, bem como promover a credibilidade de todos os seus profissionais (...) estimular o cumprimento da ética profissional e dos códigos deontológicos (...) fomentar os índices de recetividade dos diversos agentes das estruturas que participam na produção de conteúdos (...) contribuir para uma cultura de autocrítica e de prevenção de eventuais atitudes corporativistas no interior das Empresas, mas também por parte dos cidadãos a quem representam (Lei n. $\left.{ }^{\circ} 2 / 2006\right)$.

No caso do provedor do ouvinte, o cargo foi desempenhado por José Nuno Martins entre setembro de 2006 e abril de 2008, sendo posteriormente substituído por Adelino Gomes, que iniciou as funções em agosto de 2008, mantendo-se no cargo até julho de 2010. Em setembro de 2010, o cargo passou a ser desempenhado por Mário Figueiredo, que se manteve em funções até junho de 2012. A atual provedora, Paula Cordeiro, iniciou funções em setembro de 2012.
Para o desempenho da função, o provedor dispõe de uma página na Internet $^{1}$, através da qual os ouvintes podem enviar as suas críticas, reclamações ou sugestões, e de um programa semanal difundido em todas as estações da RDP; Antena 1, Antena 2, Antena 3, RDP Madeira, RDP Açores, RDP África e RDP Internacional, com uma duração mínima imposta pela lei, em que apresenta as suas opiniões e considerações em relação às mensagens recebidas, bem como outros temas que ache por bem difundir. Na página da Internet estão disponíveis os guiões de todos os programas, as emissões em podcast dos programas dos dois primeiros provedores, a legislação referente ao provedor, alguns pareceres importantes, uma apresentação do provedor, estatutos e propósitos e os relatórios de atividades de todos os provedores.

No caso do provedor do telespectador, o cargo foi desempenhado por José Manuel Paquete de Oliveira, entre setembro de 2006 e abril de 2010 ,

$1 \mathrm{http://wwl.rtp.pt/wportal/grupo/provedor}$ ouvinte/provedor.php 


\section{No sentido de}

\section{aproximar $o$}

público e os

órgãos do serviço

público de rádio

e televisão,

foram criados

os provedores

do ouvinte e do

telespectador da

Rádio e Televisão

de Portugal sendo posteriormente substituído por José Carlos Abrantes (que já tinha sido provedor do leitor do Diário de Notícias, entre abril de 2004 e julho de 2007), que desempenhou as funções de provedor entre maio de 2011 e abril de 2013. O atual provedor, Jaime Fernandes, assumiu o cargo em maio de 2013. Para o desempenho da função, o provedor dispõe de um programa semanal que é transmitido na RTP 1, RTP Madeira, RTP Açores, RDP Memória, RTP Internacional e RTP Mobile e de uma página na Internet $^{2}$, através da qual os telespectadores podem contactar o provedor, onde estão disponíveis as emissões online do programa Voz do Cidadão, a legislação referente ao provedor, alguns pareceres importantes, uma apresentação do provedor, estatutos e propósitos, bem como os relatórios de atividades.

O nome escolhido para o programa do provedor do telespectador reflete exatamente aquilo que se pretende que seja o provedor. Uma plataforma que tem por base a participação ativa

2 http://wwl.rtp.pt/wportal/grupo/provedor_tv/provedor.php dos cidadãos, uma ideia confirmada pelo primeiro provedor, Paquete de Oliveira:

Sendo um procedimento de autorregulação, o Provedor do Telespectador é fundamentalmente um mecanismo que implica os cidadãos. Não é, por isso, somente uma entidade de vigilância da ética da televisão. (...) Essencialmente é uma plataforma de diálogo entre jornalistas, programadores e telespectadores. Tal como na imprensa, o Provedor é um mediador (Oliveira, 2005: 7).

Até aqui, apresentámos a figura do provedor, nas suas diferentes conceções, como provedor do leitor, do ouvinte e do telespectador e referimos algumas ideias sobre a sua área de atuação, funções e intenções. Parece-nos importante abordar, agora, alguns contributos críticos em relação a esta figura que entrou no panorama jornalístico português há quase vinte anos, há quinze nos jornais generalistas e há cinco na rádio e televisão públicas. 


\section{A eficácia e o poder do provedor}

Marcus Minuzzi (2006: 1) levantou algumas questões quanto ao papel do provedor, ao seu poder, eficácia, autonomia e independência perante diferentes instâncias (saber, por exemplo se consegue ser independente, ao mesmo tempo, frente à empresa jornalística que o contrata e aos próprios leitores). Em relação à questão do papel do provedor, Mário Mesquita (1998: 16-17) definiu sete níveis de atuação do provedor dos leitores que, quanto a nós, também se podem aplicar aos provedores dos media audiovisuais: uma função crítica e simbólica, na medida em que debate no espaço público decisões editoriais que de outra forma não sairiam das redações; uma função mediadora que estabelece uma ponte com as audiências; uma função corretiva que tenta retificar algumas matérias tratadas de forma inverídica, inexata e incompleta, podendo recorrer à opinião de peritos; uma função persuasiva que se traduz em recomendações às hierarquias dos meios de comunicação para que adotem medidas destinadas a reparar atos lesivos dos direitos das audiências; uma função pedagógica destinada a explicar às audiências como se processam os mecanismos de produção jornalística; uma função dissuasiva que pode influenciar alguns comportamentos dos editores e jornalistas e, por fim, uma função cívica que pode promover o debate dos temas políticos, económicos e sociais.

Em relação à efetivação prática destas funções, Maria José Mata (2002: 40-41) identificou três formas de poder, "delineadas pela natureza do cargo, em si": um poder de influência decorrente das críticas e recomendações, válido em relação às hierarquias, aos jornalistas e às audiências; um poder de enquadramento social da atividade dos media, a partir da adoção de uma atitude pedagógica, tendo em vista a promoção do debate sobre a atuação dos media e um poder de correção traduzido na correção pública das falhas cometidas pelo meio de comunicação em que exerce funções. É este último tipo de poder que suscita uma das questões mais persistentes em relação ao trabalho dos provedores.

Joaquim Fidalgo, que foi provedor do leitor do jornal Público, alertou para a existência de um "conflito de lealdades" entre o provedor, a direção e a redação:

\footnotetext{
Embora pareça claro que eles devem, antes e depois de tudo, prestar contas aos leitores - pois precisamente para isso são contratados -, nem sempre a empresa que lhes paga o salário ou a redação que com eles convive dá mostras de ser capaz de "encaixar" as críticas mais duras, acabando por vezes a perguntar-se se não estará, com tudo isso, a "dar tiros no próprio pé", vendo expostas publicamente as suas insuficiências, fragilidades ou derrapagens éticas. Neste sentido, este mecanismo autorregulador, embora livre e voluntário, não é um mecanismo fácil - tanto mais que se confronta ainda com alguns vícios atávicos da "corporação jornalística", frequentemente arrogante, fechada sobre si e mais propensa a pedir contas a terceiros do que a prestar as suas próprias (Fidalgo, 2006: 525).
}

Apesar das críticas, Joaquim Fidalgo (idem) acreditava que a figura do 
provedor poderia aproximar as empresas mediáticas e os jornalistas dos seus leitores, ouvintes ou espectadores, desde que houvesse uma vontade efetiva de associar as audiências ao processo informativo do qual fazem parte.

A questão da independência é um pressuposto essencial para a credibilidade do provedor. Nesse sentido, os estatutos do provedor, devem acolher certos princípios básicos de atuação dessa entidade (Fidalgo, 2006: 526527). No caso dos provedores do serviço público de rádio e televisão, a independência está patente no estatuto constante no ponto 1 do artigo $25^{\circ} \mathrm{da}$ lei que procede à reestruturação da concessionária do serviço público de rádio e televisão:

O Provedor do Ouvinte e o Provedor do Telespectador gozam de independência face aos órgãos e estruturas da concessionária do serviço público de rádio e de televisão e respetivos operadores, sem prejuízo da remuneração que lhes é devida (Lei n. ${ }^{\circ}$ 8/2007).

No que diz respeito à eficácia, tendo por base os resultados de um inquérito realizado a jornalistas, Joaquim Fidalgo (2006: 536) assegurava que o provedor era uma figura considerada útil e eficaz pela maioria e funcionava como um suplemento que estimulava o rigor ético e a capacidade autocrítica da empresa jornalística onde exercia funções. Porém, José Nuno Martins, o primeiro provedor do ouvinte, no seu primeiro relatório de atividades, queixou-se de:

uma generalizada atitude de reserva corporativa dos Profissionais, quanto a qualquer proposta de alteração reclamada pelo Ouvinte acerca de práticas convencionadas, incidindo sobre as mais diversas áreas da atividade radiofónica. O silêncio costumava ser tradicionalmente a resposta mais comum a invetivas e sugestões recebidas, num regime instalado infelizmente próximo da imunidade. Por isso estava de certo modo preparado para que, do meu trabalho como Provedor, muitas vezes pudesse parecer a Ouvintes que nada se avançaria e que pouco iria resultar de modo rápido e evidente (Martins: 2007: 24).
Adelino Gomes, sucessor de José Nuno Martins, apresentou uma crítica semelhante, no seu relatório de atividades:

uma indiferença que não consigo classificar, num quadro geral de cortesia que registo, mas que me parece curta (à exceção dos diretores das diferentes estruturas, sempre disponíveis mesmo nos períodos em que as solicitações são mais frequentes) (Gomes, 2010: 77).

Já Mário Figueiredo, no relatório de 2011, apontou num sentido diferente:

No que diz respeito aos contactos com os profissionais, não posso referir, durante o ano de 2011, qualquer sinal de incomodidade. Bem pelo contrário. Várias foram as demonstrações de reconhecimento e até de solicitação para aconselhamento na melhoria profissional. Facto que se considera poder advir do reconhecimento de que o Provedor é um profissional do mesmo ofício (Figueiredo, 2012: 76). 
Com base no discurso dos provedores do ouvinte, presente nos seus relatórios de atividade, notámos que houve uma evolução positiva da relação do Provedor com os profissionais de rádio. Talvez não pela clara aceitação da figura do Provedor, mas sim da pessoa que desempenha a função de provedor. O tal reconhecimento a que Mário Figueiredo se referia.

Outros constrangimentos, relacionados com a administração da empresa, foram referidos por José Nuno Martins:

À época da elaboração do Relatório de 2006 entendi que não era ainda oportuno referir alguns já preocupantes indícios do que, com o decorrer dos tempos, viria a tornar- se numa soma de condicionantes e obstáculos, de natureza operacional e comportamental, ao desempenho livre das funções de Provedor do Ouvinte no seio da Empresa. (...) Porém, com o acumular dos episódios, os constrangimentos foram-se agravando em diversos planos, até ao limite do suportável.
Muito embora na primeira reunião conjunta com o anterior Presidente da Empresa, as palavras de boas intenções tivessem corrido soltas da parte deste Senhor e do Senhor Administrador a quem o Senhor Presidente delegara os contactos connosco, bem cedo percebi que, teríamos de contar mais com o nosso esforço e com a disponibilidade intelectual dos Profissionais nossos interlocutores, do que propriamente com a abertura institucional da Empresa e os seus ilustres Gestores, para nos facilitar o desempenho crítico independente (Martins, 2008: 3).

Já para Adelino Gomes, a relação com a direção da empresa foi menos conflituosa. Contudo, o antigo provedor do ouvinte, continuou bastante crítico, em relação à eficácia do provedor: "continuei a não ver sinais que indiciassem a criação de uma dinâmica de interação entre os três polos (audiência, profissionais e estrutura dirigente), propiciada pelo provedor" (Gomes, 2010: 77).
Uma posição diferente teve Mário Figueiredo:

No que diz respeito às Estruturas Diretivas, nomeadamente as que mais solicitei nestes meses (...) refira-se que não senti a mínima incomodidade ou reserva. Os pedidos de esclarecimentos e as reuniões solicitadas tiveram sempre uma resposta pronta, cordial e atempada (Figueiredo, 2012: 76).

Todavia, alertava que a relação, tanto com os profissionais como com os diretores, poderia piorar:

Se continuo a acreditar que a consideração que me têm demonstrado é consequência do reconhecimento e estima ao profissional, temo que, no futuro, eventualmente no próximo Relatório, tenha de reportar que os profissionais e os diretores também não se sentiram estimulados para responder às solicitações do provedor (Figueiredo, 2012: 86).

O facto não se consumou e as relações com profissionais e diretores 
mantiveram-se boas, durante os primeiros meses do mandato da provedora Paula Cordeiro:

Até ao momento de execução deste cargo, sou obrigada a louvar a forma como, na qualidade de provedora, já fui convidada a intervir nas emissões de rádio, para além do programa Em Nome do Ouvinte; bem como a disponibilidade demonstrada pelos profissionais e representantes das diferentes direções, em colaborar na recolha de informação e construção do programa Em Nome do Ouvinte (Cordeiro, 2013: 28).

Em relação ao primeiro provedor do telespectador, Paquete de Oliveira, apenas conseguimos perceber o seu relacionamento com as estruturas dirigentes e os jornalistas a partir dos agradecimentos deixados no último relatório de atividades. Conseguimos também aferir que este "bem estar" se deveu, sobretudo, à postura assumida pelo provedor, mesmo na redação dos seus relatórios:
Notámos que houve

uma evolução

positiva na relação

do Provedor com

os profissionais de

rádio, talvez não

pela aceitação

da figura, mas

sim da pessoa

que desempenha

o cargo

\begin{abstract}
Evitei embarcar numa certa lógica de que em televisão "quanto mais sangue", quanto mais polémica, melhor. Tenho consciência de que fui pouco incisivo, consequentemente muitas vezes pouco concreto ao apontar o erro, o exagero. Não desconheço que, como na atual vida social, a atividade comunicacional (informativa/jornalística) anda alheia na observância atenta de práticas éticas e deontológicas. Mas ainda na procura de um enriquecimento destas dimensões, julgo e defendi que a prática de portar-me como "mediador" era a via mais indicada (Oliveira, 2010: 65).
\end{abstract}

Por sua vez, José Carlos Abrantes, para além dos agradecimentos bastante semelhantes aos deixados por Paquete de Oliveira, acrescentou a cooperação dos jornalistas e diretores, inclusive através da participação direta no programa do provedor:

Um dos aspetos mais positivos e enriquecedores para o programa foi a presença dos diretores (...) 
Sempre que os solicitei obtive uma resposta de manifesta cooperação e empenho. É de louvar, também, a cooperação dos jornalistas a quem pedi esclarecimentos ou entrevistas (Abrantes, 2012: 21)

No entanto, considerou que seria necessário estreitar ainda mais as relações com os diretores jornalistas e criadores para cumprir melhor a tarefa de mediação que lhe estava atribuída (Abrantes, 2012: 39).

Em relação à questão da eficácia, as maiores críticas surgiram da parte do provedor do ouvinte, Mário Figueiredo, que defendeu, no relatório de atividades de 2010, que o formato do programa do provedor do ouvinte tinha uma eficácia reduzida e que os horários eram inadequados, bem como a duração do programa (15 minutos obrigatórios por lei), que o impediam de ser emitido em horários prime time, sendo escutado por uma margem reduzida de ouvintes (Figueiredo: 2011: 5). Essa crítica foi mantida no relatório de 2011 , acrescentando algumas anomalias técnicas e informáticas que foram, inclusive, alvo de um inquérito (Figueiredo: 2012: 27).

Mário Figueiredo, propôs no seu relatório de 2012 um aumento da intervenção do provedor em antena "eventualmente em direto e em horário nobre" (Figueiredo, 2012: 26). O que acaba por ser o reforço de uma questão já levantada por Adelino Gomes que chegou mesmo a propor uma alteração à alínea que regula a periodicidade e a duração do programa, patente da lei que estabelece as normas sobre o provedor do ouvinte e do telespectador (Gomes, 2009: 23).

José Carlos Abrantes, provedor do telespectador, no seu relatório de atividades debruçou-se também acerca da eficácia do Provedor considerando que:

a eficácia do Provedor está na crítica pública do jornalismo e dos programas. O jornalismo e a programação têm os seus próprios métodos de se conterem e expandirem para outros territórios. As reuniões, as chefias, a crítica dos pares, os códigos deontológicos são alguns dos instrumentos que têm a seu dispor.
(...) A eficácia do Provedor é, paradoxalmente, uma tarefa solitária mas também de partilha. Solitária na decisão, mas de partilha com os telespectadores, com os diretores, com os autores, com as chefias, com a equipa que trabalha no Gabinete do Provedor (Abrantes, 2012: 41-42).

Há ainda muitas arestas para limar, de forma a que a atuação dos provedores se torne mais efetiva e útil mas, como alertava Joaquim Fidalgo (2006: 541), trata-se de um processo lento cujos efeitos são refletidos a médio e longo prazo, por ser um trabalho de orientação pedagógica, mais voltado para modificar e melhorar atitudes mentais e comportamentos permanentes. Pelos exemplos que aqui trouxemos, recorrendo aos relatórios de atividades dos provedores, percebemos que a tarefa dos primeiros provedores foi bastante complicada, sobretudo por ser uma novidade e por mexer com atitudes instituídas, mas que, com o decorrer do tempo e com as ações que foram sendo tomadas, conseguiram conquistar o seu espaço e o respeito dos profissionais dos meios em que estão inseridos. Fidalgo (2006: 542) não teve 
dúvidas em afirmar que o provedor é um mecanismo frágil, limitado e imperfeito, mas é apenas um, entre muitos outros, que procura confrontar os media com as suas responsabilidades e, sobretudo, com a exigência de prestar contas ao público e parece ter um grande potencial para contrariar alguma impopularidade dos media, desde que conte com a cumplicidade dos jornalistas na tarefa de salvar o jornalismo da queda na propaganda e no divertimento, para a qual alertou Mário Mesquita, em 1999.

Foi com base nessa ideia de mediação e correção de atitudes que Adelino Gomes, provedor do ouvinte entre agosto de 2008 e julho de 2010 , traçou os seus propósitos, posteriormente publicados no relatório de atividades:

A função de provedor - defendi revelar-se-á útil na medida em que toque e faça tocar de forma atuante cada um daqueles polos, numa atividade "essencialmente polifónica". (...) Isto é, veicule as queixas, sugestões, críticas de quem ouve, oferecendo-lhes um canal de contacto mais direto; questione o campo profissional e os responsáveis, incitando o primeiro a reavaliar opções

\section{O Provedor}

é apenas um

mecanismo

que procura

confrontar os

media com as suas

responsabilidades

e parece ter um

grande potencial

para contrariar a

impopularidade

dos media, desde

que conte com

a cumplicidade

dos jornalistas técnico-profissionais, metodologias, modos de trabalho, competências, e os segundos, a fornecerem meios, criarem condições suficientes de trabalho e a conterem eventuais tentações de interferência nos conteúdos; e, por fim, leve a cada um destes polos eco do olhar dos outros, criando uma dinâmica que, quando melhor funciona é, necessariamente, criativa e, quando não, tem o mérito, ao menos, de tornar mais transparente e participada a forma de prestação do serviço público (Gomes, 2009: 17).

Apesar de todas as críticas e contingências apresentadas, os provedores foram unânimes em reconhecer a importância da existência da figura do provedor, apesar de algumas críticas que devem ser vistas de uma perspetiva construtiva.

\section{Conclusão}

Numa época em que se debate a reestruturação do serviço público de rádio e de televisão e se discute a possibilidade da participação do 
público, tendo em vista a melhoria da qualidade do serviço, o provedor surge como um dos exemplos que serve essa intenção, entre outras possibilidades e instrumentos de crítica e de autorregulação já existentes.

Não se tratando de uma análise empírica exaustiva, este estudo revela alguns aspetos que devem ser alvo de reflexão em relação às reais vantagens da existência da figura de um provedor nos meios audiovisuais de acesso livre.

A partir da leitura dos relatórios de atividades dos provedores do ouvinte e do telespectador, podemos afirmar que há uma grande diferença quanto à aceitação e ao respeito pela figura do provedor no serviço público de rádio e televisão, desde que surgiram até aos dias de hoje, o que indica uma maior aceitação da crítica, no sentido de melhorar a qualidade da informação e do compromisso com as audiências.

A participação da sociedade civil na discussão sobre os media e o jornalismo, tendo como mediador a figura do provedor, parece-nos ser vantajosa para uma maior credibilização da empresa concessionária, desde que o provedor tenha condições e autonomia para a desempenhar de forma autónoma, em conjunto com outros instrumentos de autorregulação, já existentes.

\section{Bibliografia}

Aznar, H. (2006). Comunicação responsável: A autorregulação dos media. Porto: Porto Editora.

Bertrand, C. (2002). A deontologia dos media. Coimbra: MinervaCoimbra.

Camponez, C. (2004). A crise do jornalismo face aos novos desafios da comunicação. Atas dos Ateliers do V Congresso Português de Sociologia, Associação Portuguesa de Sociologia. Consultado a 22 dezembro de 2011. Disponível em: http://www.aps.pt/cms/docs_prv/ docs/DPR46151be427116_1.pdf .

Camponez, C. (2009). Fundamentos de deontologia do jornalismo: A autorregulação frustrada dos jornalistas portugueses (1974-2007)(dissertação de doutoramento). Consultado a 21 dezembro 2011. Disponível em: https://estudogeral.sib.uc.pt/bitstream/10316/12614/3/Tese_Carlos\%20Camponez.pdf .

Cornu, D. (1994). Journalism et Vérité: Pour une éthique de l'information. Genéve: Labor et Fides.
Fidalgo, J. (2006). O Provedor do Leitor. o lugar da ética e da autorregulação na identidade profissional dos jornalistas. (Tese de Doutoramento), Universidade do Minho.

Mata, M. J. (2002). A autocrítica no jornalismo: $O$ ombudsman na imprensa nacional e estrangeira. Coimbra: MinervaCoimbra.

Mesquita, M. (1998). O Jornalismo em Análise: A coluna do Provedor do Leitor. Coimbra: MinervaCoimbra.

Minuzzi, M. (2006). O leitor no mecanismo do ombudsman de imprensa heterogeneidades e idealizações. UNIrevista, 1 (3), 1-11.

Oliveira, M. (2006). Provedor do Telespectador: Um argumento contra a Caixa de Pandora. Huelva: Grupo Comunicar.

\section{Outros recursos}

\section{Legislação}

Lei $n .^{\circ}$ 2/2006. D.R. I Série A. 32 (200602-14) 1150.

Lei $n .^{\circ}$ 8/2007. D.R. I Série. 32 (200702-14) 1138. 


\section{Relatórios dos Provedores}

Cordeiro, P. (2013). Relatório de actividade Provedor do Ouvinte. Consultado a 15 outubro 2013. Disponível em: http://www.rtp.pt/ wportal/grupo/provedor_ouvinte/ relatorioact_2012.php.

Figueiredo, M. (2011). Relatório intercalar Provedor do Ouvinte: 2010. Consultado a 9 janeiro 2013. Disponível em: http://wwl.rtp.pt/ wportal/grupo/provedor_ouvinte/ relatorioact_2010.php.

Figueiredo, M. (2012). Relatório de atividade do Provedor do Ouvinte (2011). Consultado a 9 janeiro 2013. Disponível em: http://www.rtp.pt/ wportal/grupo/provedor_ouvinte/ relatorioact_2011.php.

Gomes, A. (2009). Relatório do Provedor do Ouvinte: 2008. Consultado a 08 janeiro 2013. Disponível em: http:// wwl.rtp.pt/wportal/grupo/provedor_ ouvinte/relatorioact_2008.php.

Gomes, A. (2010). Relatório do Provedor do Ouvinte: 2009. Consultado a 8 janeiro 2013. Disponível em: http:// wwl.rtp.pt/wportal/grupo/provedor_ouvinte/relatorioact_2009. php.
Martins, J. N. (2007). Relatório de actividade do Provedor do Ouvinte do serviço público de radiodifusão sonora: Ano de 2006. Consultado a 7 janeiro 2013. Disponível em: http:// wwl.rtp.pt/wportal/grupo/provedor_ouvinte/relatorioact_2006.php.

Martins, J. N. (2008). Relatório Final de Actividade do Provedor do Ouvinte do Serviço Público de Radiodifusão Sonora: 2006/2008. Consultado a 8 janeiro 2013. Disponível em: http:// wwl.rtp.pt/wportal/grupo/provedor_ouvinte/relatorioact_2007.php.

Oliveira, P. (2007). Relatório do Provedor do Telespectador da RTP: 2006. Consultado a 10 janeiro 2013. Disponível em: http://wwl. rtp.pt/wportal/grupo/provedor_tv/ relatorioact_2006.php.

Oliveira, P. (2008). Relatório do Provedor do Telespectador da RTP: 2007. Consultado a 10 janeiro 2013. Disponível em: http://wwl. rtp.pt/wportal/grupo/provedor_tv/ relatorioact_2007.php.

Oliveira, P. (2009). Relatório do Provedor do Telespectador: 2008. Consultado a 10 janeiro 2013. Disponível em: http://wwl.rtp.pt/wportal/grupo/ provedor_tv/relatorioact_2008.php.
Oliveira, P. (2010). Relatório do Provedor do Telespectador: 2009. Consultado a 10 janeiro 2013. Disponível em: http://wwl.rtp.pt/wportal/grupo/ provedor_tv/relatorioact_2009.php. Oliveira, P. (2011). Relatório do Provedor do Telespectador: 2010. Consultado a 10 janeiro 2013. Disponível em: http://wwl.rtp.pt/wportal/grupo/ provedor_tv/relatorioact_2010.php . 